\title{
APPLICATION OF MUSCLE INHIBITING TECHNIQUES TO CHILDREN WITH CEREBRAL PALSY
}

\author{
Mariya Gramatikova \\ Department of Kinesitherapy, Faculty of Public Health, Healthcare and Sports, \\ South-West University"NeofitRilski”, Blagoevgrad, Bulgaria.
}

\section{SUMMARY}

Purpose: The research aims to conduct a pilot study and monitor the effectiveness of a method of muscle-inhibition techniques applied to soft tissue contractures of the hip complex in children with cerebral palsy.

Material/Methods: eight children with spastic quadriparesiswere studied by means of goniometric measurements, palpatory evaluations of the muscle tone, and tests to detect myo-articular contractures in the hip complex. The test battery was applied on the children both before and after they had gone through 30-day physiotherapy that included sessions of myo-articular mobilisation, post-isometric relaxation and stretching. Each of the muscleinhibiting techniques was applied 6-8 times, accompanied by stretching in the final range that continued until the co-contraction disappeared, followed by restretching enabled by the gained volume of movement in the joint. The duration of the stretching varied from one child to the next depending on the extent of activation of the Golgi reflex. At the maximum range of motion, the stretch hold was about 50-60 seconds.

Results: The results of the study show that $\mathrm{X}$ of the passive hip extension on the first day was $3.7^{0} \pm 4.282$, indicating its severe limitation. After the 30-day physiotherapy, the mean values reached $12,19^{0} \pm 4,07^{0}$, in other words, the indicator had improved by $8,44^{0} \pm 4,07^{0}$. On the first day, passive flexion of $X=103.1^{0} \pm 13.77^{0}$ was established in the hip joint; in the second study, this value was $X=120.0^{0} \pm 10.17^{0}$. Flexibility in the hip joint increased by $16.9^{0}$. The abduction in the joint on the first day of the study had values of $X=20.94 \pm 7.793$, which by the 30 th day had increased to $36.25 \pm 8.466$. P-values indicate that the physiotherapy model applied had resulted in statistically significant differences in the test parameters.

Conclusion: The applied method of muscle-inhibition techniques is effective in children with spastic quadriparesis and restores the soft tissue and articular mobility of the hip complex.

Keywords: physiotherapy, pediatrics, neurology, spastic, contractures, stretching, mobilization

\section{INTRODUCTION}

Child cerebral palsy, in its double hemiplegic form, is the worst form of motor deficit. Hyper tonus of the flexors in the hip, predominantly adduct, flexor, andinternal rotary contracture [1] prevail, limiting the range of motion in the hip joint. The neurological research conducted reveals the presence of conditions including central quadriparesis (with spastic increased tone - hand flexion and extension in the lower limbs), contractures and very live tendon reflexes. There is a muscle imbalance, gradually developing contractures and deformations and the creation of a pathological motor stereotype [2, 3]. Spasticity control is a problem in the treatment of children with cerebral palsy, which prevents their functional recovery and mobility $[4,5,6]$. The continuous application of passive stretching and mobilisation to such children improves their range of motion and reduces the spasm of their muscles around the target joint. Passive stretching is widely used in patients with cerebral palsy in the belief that the shortening or contractures of the soft tissues can be corrected and extended $[7,8,9]$.

\section{PURPOSE}

The research aims to pilot a study and monitor the effectiveness of a methodology for muscle-inhibition techniques applied to soft tissue contractures of the hip complex in children with spastic quadriparesis.

\section{MATERIAL/METHODS}

The research was conducted in a day centre for children with disabilities in the city of Blagoevgrad. Eight children, aged 4-10 and having spastic cerebral palsy, were studied. The functional study was carried out both before and after a 30-day period of physiotherapy that included sessions of myo-articular mobilisation, post-isometric relaxation and stretching of the lower limbs. The empirical material was processed statistically. A variation analysis was performed using the Prism3 scoring system. The statistical significance of the differences in the mean values of the indicators was established for more than two samples by applying the Wilcoxon and Maan Whitney and Freedman ANOVA (Dunn's test) criteria [10, 11]. 


\section{Methodology of Physiotherapy}

Goal: Improve myo-articular laxity and the passive range of motion in the hip complex.

\section{Tasks:}

1. Analytical impact on soft tissue contractures to increase laxity and their ability to sustain tension.

2. Analytical impact on the hypertonic muscles through muscle inhibiting techniques to reduce muscle hypertonia.

3. Reducing the number, duration and strength of the antagonists' co-contractions in the various hip joint movements. joint.

4. Improving the passive range of motion in the hip

\section{Functional study:}

goniometry of the hip joint - a measurement of the passive range of motion: flexion, extension, abduction;

- a palpated evaluation of the muscular tone of the hip complex;

- testing for the detection of myo-articular contractures in the hip complex.

The test battery was applied both before and after 30 days of physiotherapy.

Means: The methodology includes muscle-inhibitory techniques: myo-articular mobilisation, post-isometric relaxation (antagonist co-contraction) and passive stretching for the adductors, extensors and flexors of the hip joint bilaterally.

Dosage: Each of the muscle-inhibiting techniques was applied 6-8 times by stretching in the final volume, which continued until the antagonist's co-contraction disappeared, next stretching the gained joint volume in the joint until subsequent co-contraction, and then reaching the final range of motion.
Rate of speed - slow hold.

The duration of the stretching was adapted to the children's individual level of activation of the Golgi reflex (until the antagonist's co-contraction disappears). Upon reaching the maximum range of motion, the stretch hold was about 50-60 seconds. The procedure lasted 30 minutes.

The physiotherapy was applied for 30 days.

Indications for the application of manual myo-articular mobilisation and stretching:

- $\quad$ Muscle shortening or contractures;

- Abnormal muscle hyper tone, including spas-

ticity;

- $\quad$ Limited range of motion and more.

Contraindications for physiotherapy:

- $\quad$ The acute phase of neurological symptoms;

- A lesion on the spinal cord;

- Deterioration of the neurological symptoms;

- $\quad$ Acute inflammatory processes, tumours, etc.

\section{RESULTS AND ANALYSIS}

The results of the study show that $\mathrm{X}$ of the passive extension in the hip joint on the first day was 3.70 4.282 , pointing to a strong limitation. After the 30-day physiotherapy, the mean values reached $12,19^{0} \pm 4,07^{0}$, that is, the indicator had improved by $8,44^{0} \pm 4,070^{\circ}$. The variability of the results decreased from $\mathrm{V} \%=114.18 \%$ in the first study to $\mathrm{V} \%=33.39 \%$ in the final study; this trend was also observed with regard to two other indicators. The trend reflects the decrease in the variations exhibited by the children during the recovery process of the passive extension. The $\mathrm{P}=$ 0.0032 values showed a statistically significant difference in the mean values of the indicator before and after one month of physiotherapy, and that the muscle-inhibiting techniques improved the passive extension in the hip joint.

Table 1. Statistical indicators for the extension, flexion and abduction of the hip joint, before and after 30 days of physiotherapy

\begin{tabular}{|c|c|c|c|c|c|c|}
\hline & $\begin{array}{c}\text { hip extension } \\
1 \text { day }\end{array}$ & $\begin{array}{c}\text { hip extension } \\
30 \text { day }\end{array}$ & $\begin{array}{c}\text { hip flexion } \\
1 \text { day }\end{array}$ & $\begin{array}{c}\text { hip flexion } \\
30 \text { day }\end{array}$ & $\begin{array}{c}\text { hip abduction } \\
1 \text { day }\end{array}$ & $\begin{array}{c}\text { hip abduction } \\
30 \text { day }\end{array}$ \\
\hline$\underline{X}$ & 3,750 & 12,19 & 103,1 & 120,0 & 20,94 & 36,25 \\
\hline SD & 4,282 & 4,070 & 13,77 & 10,17 & 7,793 & 8,466 \\
\hline V\% & $114,18 \%$ & $33,39 \%$ & $13,35 \%$ & $8,47 \%$ & $37,22 \%$ & $23,35 \%$ \\
\hline P & 0,0032 & 0,0004 & 0,0287 \\
\hline
\end{tabular}

Passive flexion in the hip joint, at a value of $\mathrm{X}=103.1^{0} \pm 13.77^{0}$, was determined on the first day of the study and at a value of $X=120.0^{0 \pm} 10.17^{0}$ in the second study. The results show that, after physiotherapywas applied, children's hip flexion increased by $16.9^{\circ}$. Here again, the variance decreases from $\mathrm{V} \%=13.35 \%$ in the first study to $\mathrm{V} \%=8.47 \%$ in the second study. P-values showed $(\mathrm{P}=0.0004)$ that the physiotherapy model applied resulted in a statistically significant difference in the indicator in favour of the hip joint flexion at day 30. On the first day of the study, the children's hip joint abduction measured $X=20.94 \pm 7.793$, which increased to $36.25 \pm 8.466$ by the 30 th day. The V\% tended to decrease and from $37.22 \%$ to $23.35 \%$, which is a sign of improving the consistency of the results in the group. The $\mathrm{P}(0.0287)$ values showed a statistically significant improvement in abduction after the physiotherapy sessions. 


\section{DISCUSSION}

Teaching a normal motor stereotype to children with cerebral palsy including by creating motor models and locomotion that they can emulate, requires, above all, a sufficient range of motion of their myo-articular apparatus. Otherwise, any motor training is doomed to failure. That is why I believe that, in the physiotherapy programme, there must be some means of muscle-inhibition techniques, restoration, maintenance of myo-articular laxity, and contracture prevention. In this pilot study, the results show the good effect of applying muscle-inhibiting techniques. During the study, there was an improvement in the range of motion in the hip, as well as a decrease in the number, strength and duration of the co-contractions of the antagonist muscles that impeded normal physiological movement. These positive trends increased in each subsequent procedure.

\section{CONCLUSION}

The applied method of physiotherapy, including myo-articular mobilization, post-isometric relaxation and stretching, is effective in children with cerebral palsy spastic quadriparesis and restores the soft tissue and articular mobility of the hip complex.

\section{REFERENCES:}

1. Zhelev V. (Editor). [Physiotherapy in pediatrics: textbook] [in Bulgarian] Sofia: ed. Avangard Prima; 2012. pp.277.

2. Deleva R. [Management of child cerebral palsy - inexhaustible opportunities of physiotherapy] [in Bulgarian] Health Economics and Management, Steno - Varna. 2017; 1(63):2429.

3. Mitova St, Frequency and Prevalence of postural disorders and spinal deformities in children of primary school age. Screening, Research in $\mathrm{Ki}$ nesiology. 2015; 43(1):21-24.

4. Herskind A, RitterbandRosenbaum A, Willerslev-Olsen M, Lorentzen J, Hanson L, Lichtwark G, et al. Muscle growth is reduced in 15 month old children with cerebral palsy. Dev Med Child Neurol. 2015; 58(5):485-491. [Crossref]
5. Parashkevova P, Deleva R, Mincheva P, Andreev A. A study on use of neurodynamic tests among neurorenabilitation professionals. $J$ of IMAB. 2019 Jan-ar;25(1):24382442. [Crossref]

6. Avramova M. [The effect of the application of specialized kinesitherapeutic methods in children with cerebral palsy.] [in Bulgarian] Knowledge Int J. Budva, Montenegro. 2018 May; 23.2:707-711. [Internet]

7. Pin T, Dyke P, Chan M. The effectiveness of passive stretching in children with cerebral palsy. Dev Med Child Neurol. 2006 Oct;48(10):85562. [PubMed]

8. Chongov B, Alexiev V, Georgiev H, Kalinov K, Dimitrova E. Correlation between scoliosis deformity type and trunk symmetry before and after schroth physiotherapeutic exercises. $C$
R Acad Bulg Sci. 2017 Nov;70(10): 1455-1462. [Internet]

9. Mitova St. (Editor). [Screening for Postural Disorders and Spinal Distortions in Primary School Children: monograph.] [in Bulgarian] Blagoevgrad: University ed. „N. Rilski”; 2017. pp.174.

10. Karashtranova E. (Editor). [Interactive training on probabilities and statistics-textbook of a monographic nature.] [in Bulgarian] University Publishing House SWU „Neofit Rilski”, Blagoevgrad. 2010. pp.75-77.

11. Karashtranova EL, Stoimenova EA. [Analysis of the efficacy of experimental teaching on combinatorics, probability and statistics at high school.] [in Bulgarian]. Mathematics and Education in Mathematics, Varna. 2007. pp.376-382.

Please cite this article as: Gramatikova M. Application of muscle inhibiting techniques to children with cerebral palsy. J of IMAB. 2020 Oct-Dec;26(4):3353-3355. DOI: https://doi.org/10.5272/jimab.2020264.3353

Received: 24/09/2019; Published online: 02/10/2020

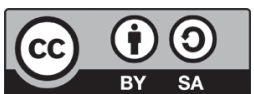

\section{Address for correspondence:}

Assoc. Prof. Mariya Gramatikova, PhD

Department of Kinesitherapy, Faculty of Public Health, Healthcare and Sports, South-West University "NeofitRilski" Blagoevgrad, 66, Ivan Mihaylov Str., 2700 Blagoevgrad, Bulgaria. E-mail: mari_gramatikova@abv.bg 